ARCHIVO ESPAÑOL DE ARTE, LXXXVI, 343

JULIO-SEPTIEMBRE 2013, pp. 181-200

ISSN: 0004-0428

\title{
ARQUITECTURAS PARA LA MÚSICA: LAS CAJAS DE ÓRGANO DE LA PARROQUIA MATRIZ DE SAN JUAN BAUTISTA DE MARCHENA (SEVILLA)
}

\author{
Manuel Antonio Ramos SuÁrez \\ Universidad de Sevilla
}

\begin{abstract}
En este trabajo se hace un análisis de las cajas de dos órganos que se conservan en la iglesia parroquial de San Juan Bautista de Marchena. Partiendo del conocimiento del espacio coral conservado desde el primer tercio del siglo XVIII que no ha sucumbido a los cambios litúrgicos del siglo XX, se presenta un estudio histórico, artístico y estilístico de las cajas que guardan los instrumentos musicales conservados íntegramente y restaurados en los últimos años del siglo XX, así como su comparación con otras cajas. Se trata de dos muebles de estilo barroco y neoclásico respectivamente que custodian dos instrumentos únicos también distintos en su estética musical.
\end{abstract}

Palabras clave: Caja de órgano; Parroquia de San Juan; Marchena (Sevilla); Juan Chavarría organero; Francisco Rodríguez organero; Francisco de Acosta “el mozo” arquitecto y tallista.

\section{ARCHITECTURES FOR MUSIC. ORGAN CASES IN THE PARISH CHURCH OF SAINT JOHN THE BAPTIST IN MARCHENA (SEVILLE)}

This study offers an analysis of the cases of two organs preserved in the parish church of Saint John the Baptist in Marchena. Taking as a starting point the fact that the choral space has remained constant since the first third of the 18th century, and has not succumbed to the liturgical changes of the 20th, the author presents a historical, artistic and stylistic study of the organ cases, as well as a comparison with other cases. These two pieces of furniture differ stylistically, one is baroque and the other neoclassical, and they hold two equally unique instruments, different as well in their musical esthetic. Both were completely restored during the last years of the 20th century.

Key words: Organ case; Parish church of Saint John the Baptist, Marchena (Seville); Juan Chavarría organist; Francisco Rodríguez organist; Francisco de Acosta "the younger" architect and wood carver.

No cabe duda que el coro es uno de los elementos esenciales en la configuración espacial de las catedrales, colegiales, o incluso iglesias parroquiales. En España responde a una tipología peculiar al ubicarse en los últimos tramos de la nave principal, cercano a la puerta de los pies de la iglesia. Tal situación permitía deambular a su alrededor, aspecto primordial para el ceremonial litúrgico procesional. En el caso que nos ocupa, la iglesia matriz de San Juan Bautista de Marchena (Sevilla), se ha sabido mantener y conservar intacto ese espacio coral con todo lo 
que conlleva ${ }^{1}$. Tal cual hoy se ve, se realizó a principios del siglo XVIII, habiéndose enriquecido con el paso del tiempo. Su conservación ha posibilitado que los elementos estructurales y funcionales se encuentren tal como se concibieron en su momento, sin perder su unidad ni autenticidad. Así, ha sucedido con la sillería, los elementos decorativos del trascoro, el facistol y los órganos tanto el del lado del evangelio, como el de la epístola.

La sillería que se conserva actualmente es obra de Juan de Valencia con trazas de Jerónimo Balbás realizada entre los años 1711 y $1717^{2}$, si bien es cierto que antes de esa fecha existió otra sillería, obra de Jerónimo Hernández y Juan de Oviedo ${ }^{3}$. En 1717 se realizó la solería contrastada de jaspe blanco y negro por José Peredo, vecino de Osuna ${ }^{4}$. Por lo que respecta a la parte arquitectónica, y posiblemente con la dirección de Alonso Moreno ${ }^{5}$ todo el trascoro fue trabajado y decorado con yeserías por José Carmona y Juan José González Cañero, maestros de Écija, concluyéndose en $1720^{6}$. En la hornacina del trascoro se situó una imagen de Nuestra Sra. del Rosario, patrona de la localidad, obra de Tomás Antonio Balsedo ${ }^{7}$. El trabajo se remató con la colocación de un basamento de jaspe por el cantero moronense Manuel González, también supervisado por Alonso Moreno ${ }^{8}$. Años más tarde se contrata con el pintor Carlos de Aponte unos lienzos con "atributos" de San Juan Bautista, ${ }^{9}$ así como las cartelas que aparecen decoradas con el anagrama de la Virgen, la cruz de San Juan, ... entre otros ${ }^{10}$. A esa nueva estética barroca hay que añadir la re-

\footnotetext{
${ }^{1}$ No ha sucedido así en otros muchos lugares. Con los cambios que ha experimentado la liturgia de la Iglesia Católica, y más concretamente en el pasado siglo, muchos de los templos que conservaban esta estructura la han perdido. Varios son los motivos que han llevado a su desaparición. Uno de ellos es la pérdida del uso litúrgico para el que fue concebido, y sobre todo, porque resultaba ser un obstáculo para visualizar las ceremonias que se desarrollaban en el altar mayor. En esa extensa relación de lugares se incluyen pequeños templos, colegiales e incluso catedrales. La pérdida del espacio coral traía consigo, en el mejor de los casos, que los bienes muebles se situasen por diversas dependencias del templo o se conservasen a los pies de la misma iglesia o en la cabecera, como ha sucedido con muchas sillerías o con las cajas de órgano que se colocaban en una tribuna sobre la puerta de los pies. Estos cambios de ubicación podían provocar la pérdida de identidad, estilo y una amplia transformación del bien en cuestión. En el peor de los casos, suponía la desaparición de ese espacio y de su mobiliario integrado por la sillería, facistol, caja de órgano, o incluso pinturas y esculturas que decoraban los trascoros. Algunos ejemplos pueden ser la Catedral de Valladolid, la de Santiago de Compostela, la de Granada, ... y otros más cercanos como la Colegial del Salvador de Sevilla, la Colegiata de Osuna (Sevilla), ... NAvASCuÉs Palacios, 1998. Un trabajo más divulgativo en Navascués Palacios, 2000: 112-114.

2 De las circunstancias que se sucedieron a la hora de adjudicar la obra y de todo el proceso constructivo de la misma, Ravé Prieto, 1982: 29-33.

${ }^{3}$ Archivo Parroquial de San Juan de Marchena (APSJM), Libro de cuentas de fábrica. A-5. Años 1578-1584. $1^{\mathrm{a}}$ visita, f. 378r. El coro se cerraba con reja de madera realizada por Juan de Oviedo y Gaspar del Águila. APSJM, A-6. Años $1585-1597,3^{\mathrm{a}}$ visita, $\mathrm{s} /$ f. Posteriormente le fue añadida una tribuna diseñada en su parte arquitectónica por Vermondo Resta, maestro mayor del Arzobispado. APSJM, A-6, 4a visita, f. 396v. Se dice literalmente "A Bermondo Resta por que vino a dar la trasa de la dicha tribuna". La parte escultórica la hizo Luis de la Haya y su hijo Diego. Recibo fechado en 4 de enero de 1617. APSJM, A-8, $1^{\text {a }}$ visita, ff. 79v.-80r. El coro pasó a ubicarse en las iglesias de San Sebastián y Santa María de la Mota de esta localidad. APSJM Libro de cuentas de fábrica, A-21, Años 1719-1725, visita de 1722, p. 256.

${ }^{4}$ APSJM, Libro de cuentas de fábrica, A-20, Años 1710-1719, visita de 1717, pp. 327-328. Por el precio de cuarenta reales cada vara se obligaba también a hacerlas y solar el coro.

5 Arenillas, 2003: 172-174

${ }^{6}$ Arenillas, 2003: 173. Fernández Martín, 2000: 33-34, (lám. 11).

7 APSJM, Libro de cuentas de fábrica, A-30, Años 1755-1757, p. 435. La Fábrica pagó a Balsedo un recibo de 150 reales por la hechura de la imagen fechado en 20 de noviembre de 1757.

8 Arenillas, 2003: 173. Está fechado en el basamento de jaspe del trascoro, debajo de la hornacina. "AÑO DE 1720 ". Archivo de Protocolos Notariales de Marchena, leg. 278. ff. 191v.-192v. Escritura del contrato. Marchena, 3 de octubre de 1719.

9 Arenillas, 2003: 174. Se contrataron en el año 1734. En la actualidad se conserva un lienzo con escenas de la vida de San Juan Bautista.

${ }^{10}$ En la actualidad no son apreciables. Para poder ver cómo estaba decorado, SANCHO CORBACHO, 1984: lám. 171.
} 


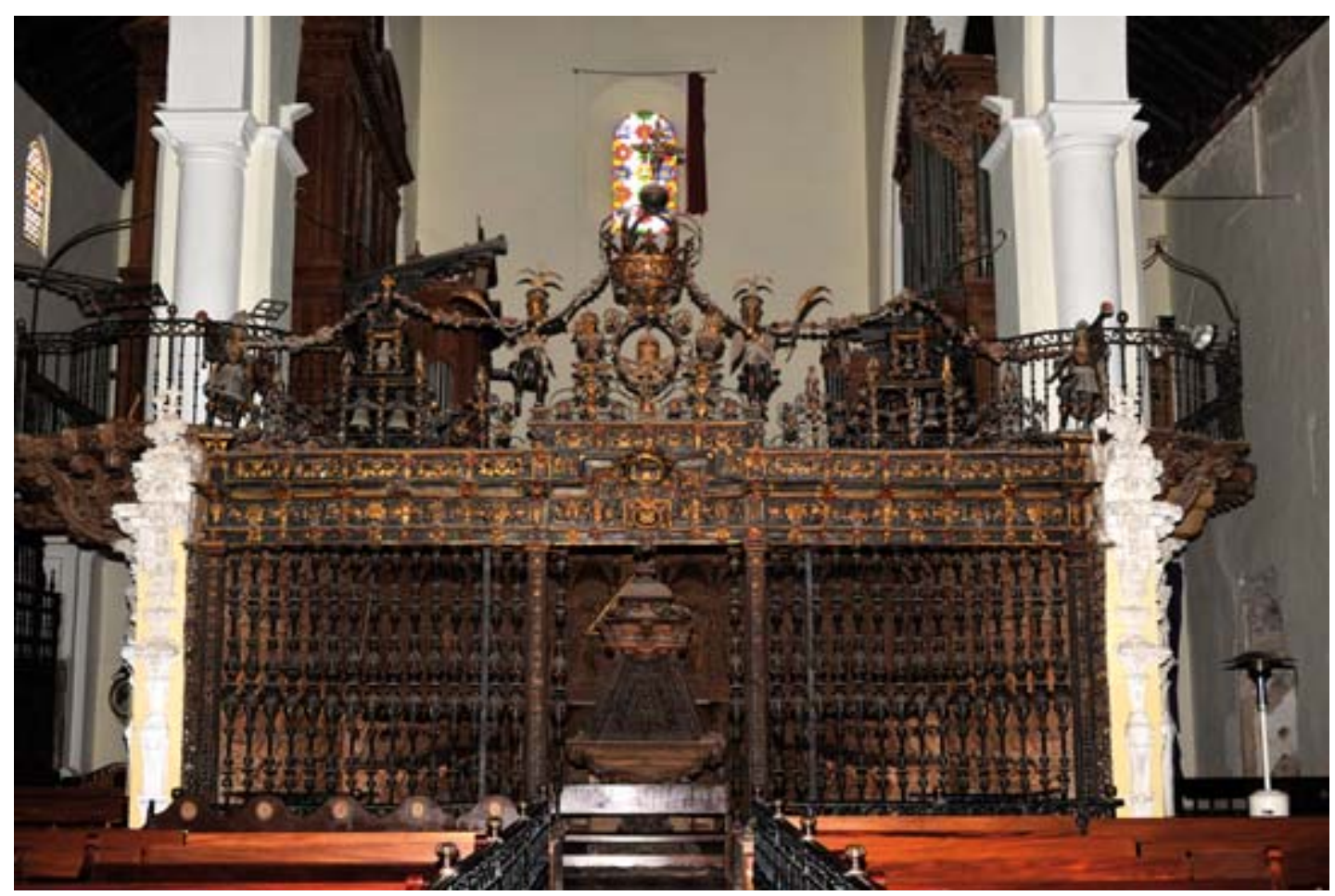

Fig. 1. Coro, reja y cajas de órganos. Iglesia Parroquial de San Juan. Marchena (Sevilla). Fotogr: Juan Antonio Campos Espina.

alización del facistol en el año 1735 por Felipe Fernández del Castillo con las trazas que en su día hizo Jerónimo de Balbás ${ }^{11}$. El conjunto se cierra por una artística reja de hierro forjado realizada por Cristóbal de los Ríos, herrero de la localidad ${ }^{12}$. Se presenta con un único cuerpo y un gran remate sobre la puerta de entrada destacando una gran corona real flanqueada por dos ángeles con palmas en las manos. Este remate se une por unas guirnaldas a sendas espadañas con tres campanas cada una situadas sobre cada uno de los paños de rejería. De éstas parten nuevas guirnaldas que rematan en otros dos ángeles trompeteros en acción de tocar. Toda la reja aparece profusamente decorada, policromada y dorada en algunas de sus partes ${ }^{13}$ (fig. 1).

Con el estreno del nuevo coro, se vio conveniente reformar el antiguo órgano que en 1620 hizo el organero Enrique Franco. Para ello, en 1724 se contó con el organero Salvador García y con su hijo $^{14}$. Esa reforma del instrumento llevó aparejada una transformación de su caja, tal vez, más acorde con la estética barroca que ofrecía el nuevo espacio coral. Y se pagó a Lorenzo Pérez, maes-

11 Ravé Prieto, 1986: 71.

12 Arenillas, 2003: 173-174. La reja se había contratado en 1732, concluyéndose en 1742. Parece ser que los últimos pagos se hacen a José y Juan de los Ríos, hijos y herederos del herrero. APSJM, Libro de cuentas de Fábrica, A-26, Años 1742-1744, p. 426.

13 El dorado y policromado de la reja del coro corrió a cargo del pintor Francisco Palomino. APSJM, A-30, Años 1755-1757, p. 434. Para conocer algún aspecto más sobre esta zona del templo, RAVÉ PRIETO, 2006.

14 APSJM, Libro de cuentas de Fábrica, A-21, Años 1719-1725, pp. 338-339. 
tro carpintero, por componer y aderezar la caja del coro, afianzar "la cañonería", la caja de ecos, e incluso colocar los andamios para pintarlo ${ }^{15}$. El trabajo de pintar la caja corrió a cargo de Andrés del Castillo, que además pintó las barandillas de la tribuna ${ }^{16}$.

\section{El órgano del evangelio o Chavarría}

Sin embargo, esa inquietud por reformar el viejo órgano y su caja dio paso, años más tarde, a la construcción de uno nuevo para adaptarse a los nuevos gustos musicales y estéticos de la época. Esto fue posible gracias a la bonanza económica que por esos años vivió la iglesia hispalense ${ }^{17}$. Esa situación se plasmó en las numerosas creaciones artísticas como las obras de arreglo y mejora que se hicieron tras el terremoto de Lisboa de 1755, la construcción de la nueva Parroquia de San Sebastián, la realización de la cilla, la casa-fábrica, ... o la adquisición de numerosos enseres y ornamentos, entre otros.

La principal fuente documental que se posee para conocer la realización del órgano es un documento que apareció en el secreto del instrumento. Dice literalmente

Se empesó este órgano día 4 de mayo y se finalisó día 17 de agosto año de 1765. Lo iso don Juan de Echabarría organero de la Santa Yglesia de Sevilla natural de la ciudad de Estella reynado de Nabarra. Trabajaron en el Miguel García natural de Esija y Julián Platero natural de la villa de Cartalla. La tribuna la hisieron Juan de los Ríos maestro de serrajero, Alonso Mesón maestro de carpintero, Francisco Nabarro maestro de albañil, todos tres maestros de la fábrica de esta yglesia ... ${ }^{18}$.

Gracias a este documento, resulta claro que el nuevo instrumento fue realizado por el organero Juan de Chavarría ${ }^{19}$. Sin embargo, por lo que respecta a la construcción de su caja, la información aportada en este escrito no resulta esclarecedora. Tras la lectura del texto del secreto lo que se puede plantear es que a pesar de la extensa y detallada relación de personas que trabajaron en su realización no se citó a nadie como constructor de su caja. El sochantre y cronista del texto del secreto, José de Ojeda, situó a continuación del organero a dos personas que "trabajaron en él"; Miguel García, natural de Écija y Julián Platero, natural de Cartaya. Poco más se conoce de estos dos trabajadores que participaron en su construcción. Analizando la bibliografía y documentación existente sobre los trabajadores del mundo de la madera en Écija, los resultados no han sido satisfactorios ${ }^{20}$. Es preciso plantear alguna hipótesis sobre quién o quienes fueron los artífices materiales de la misma.

La primera dificultad que nos encontramos al determinar quién realizó la caja del instrumento, puede venir dada por el modus operandi de los organeros. Éste, en palabras de Jambou, es el director

15 APSJM, Libro de cuentas de Fábrica, A-21, Años 1719-1725, pp. 300, 317-318.

${ }^{16}$ APSJM, Libro de cuentas de Fábrica, A-21, Años 1719-1725, pp. 339-340. Se desconoce cómo pudo ser esa caja. Del Castillo era un pintor y dorador, vecino de la localidad, que posteriormente en 1730, trabajó pintando y dorando el sagrario nuevo de la misma parroquia. Villa Nogales, Mira Caballos, 1993: 153.

${ }^{17}$ Martín Riego, 1990. Más concretamente para la iglesia local, Martín Riego, 2003: 9-62.

${ }^{18}$ Este dato se publicó por Ramírez Palacios, 1987: 157.

${ }^{19}$ La autoría del mismo también se confirma por un pago realizado a Chavarría en el que se dice que "hiso el nuevo órgano de la Yglesia de Señor San Juan y realejo de la de Santa María, ...” APSJM, Libro de cuentas de fábrica, A-32, Años 1767-1769, f. 383, pago fechado el 12 de septiembre de 1766. Para conocer algún dato más del organero, RAmíreZ Palacios, 1987: 153, así como de las características técnicas del instrumento en AYARRA JARNe, 1998: 185-186.

${ }^{20}$ Aunque se conoce una familia con el apellido García, no aparece ningún miembro con este nombre. FernáNDEZ MARTín, 1994: 110-111. También se han consultado las escrituras notariales de la ciudad de Écija de estas fechas, por si se hubiese levantado escritura de la construcción de la misma, con resultado infructuoso. 
de la construcción del órgano. Su trabajo pone en funcionamiento varios oficios, desde el negociante de la madera o metal hasta tallistas, retablistas, ensambladores, ... o incluso arquitectos. En la mayoría de los casos, el conjunto de la obra se confiaba al organero, teniendo éste que costear el instrumento y la caja. En contadas veces, los que tenían la doble formación de organero y retablista, ejecutaban la totalidad del mismo; en la mayoría de los casos confiaban la obra del mueble a un artesano del gremio de los tallistas, ensambladores o retablistas. Y sólo para proyectos de cierta envergadura se unían los expertos de la organería, la arquitectura y la talla para su realización $^{21}$. No se debe olvidar, que las cajas tenían una finalidad concreta. Servían para proteger al instrumento de posibles agresiones, así como del polvo. Este trabajo, aunque lo podían realizar los mismos organeros o ayudantes de su taller, posteriormente se buscó compaginar la funcionalidad con la estética, resultando algunos ejemplos muy atractivos. Sumamente reveladores del proceso constructivo del órgano, son el expediente de construcción del mismo, su contrato o los pagos efectuados por la fábrica parroquial. Sin embargo, para este instrumento no se conoce ninguna de estas fuentes ${ }^{22}$. No obstante, se conservan los expedientes de construcción de los órganos de la iglesia parroquial de Espera (Cádiz) y de Cazalla de la Sierra (Sevilla), ambas obras del organero Chavarría. En ellos, se le confía la construcción tanto en su parte instrumental como en lo que respecta al mueble. En una de sus clausulas se manifiesta cómo hacer la caja y poco más, sin ofrecer ningún nombre vinculado a la construcción de la misma ${ }^{23}$.

Más información la aporta el mismo mueble. Se trata de un gran órgano con cadereta con una fachada configurada en dos cuerpos. El primero y más bajo alberga el teclado, así como todos los elementos internos del instrumento. No posee ninguna decoración salvo paneles geométricos. El segundo cuerpo está formado por cinco castillos, tres torreones y dos dobles subdivididos en altura. Éstos recogen los tubos menores del flautado en el inferior y tubos "canónigos" que únicamente tienen valor estético en el superior ${ }^{24}$. La separación entre los distintos castillos que articulan el cuerpo principal de la caja está decorada por hojas y frutos volumétricos, que aparecen también en los laterales de la caja, articulando ésta. Los castillos se decoran con motivos de rocalla. Todo el conjunto se remata en una gran cornisa o entablamento de formas mixtilíneas que une los elementos anteriores. A su vez, está rematada por una crestería donde abundan principalmente rocallas, elementos vegetales, ... presentando en el centro una cartela que alberga la cruz de malta o de San Juan. La línea de unión entre un cuerpo y el superior viene dada por la colocación de los tubos de la trompetería de gusto hispano, que se coloca en forma de abanicos y parten de los tres castillos (fig. 2). Los laterales se articulan, además de las cenefas de flores y frutos por la colocación de sendos castillos, en los que se encuentran las contras, que han sido simuladas con estaño buscando la estética y armonía del mueble y dando continuidad a la fachada. Por lo que respecta a la fachada que da a la nave aparece sin decoración, salvo unas guirnaldas de frutos trabajadas toscamente que corren verticalmente por el mueble. Desde aquí y a través de unas puertas se accede al interior del instrumento. La caja del gran órgano está hecha de madera de pino para albergar los tubos de mayores dimensiones que son de ocho pies, unos tres metros de

21 JAMBOU, 1983: 229-230.

${ }^{22}$ No se conoce el expediente de construcción del instrumento, ni el posible contrato, si es que se llevó a efecto. Tampoco se conserva en el archivo parroquial el libro de fábrica que abarcaría los años 1762 a 1766 , fecha de su construcción.

${ }^{23}$ Esta información se ha extraído de los expedientes de ambos órganos. Se han consultado copias cedidas por don Antonio Ramírez Palacios a quien agradezco. Los originales se conservaban en el Archivo General del Arzobispado de Sevilla, si bien el del órgano de Espera pasó al Archivo Diocesano de Jerez de la Frontera. Además se ha consultado en el Archivo Histórico Provincial de Cádiz, sección de Protocolos Notariales, la escribanía de Espera para los años 17601764 sin encontrar ninguna referencia a la construcción del órgano de esa localidad.

24 Para éste y otros aspectos técnicos se ha seguido lo expuesto en la descripción de Grenzing, s/f. 


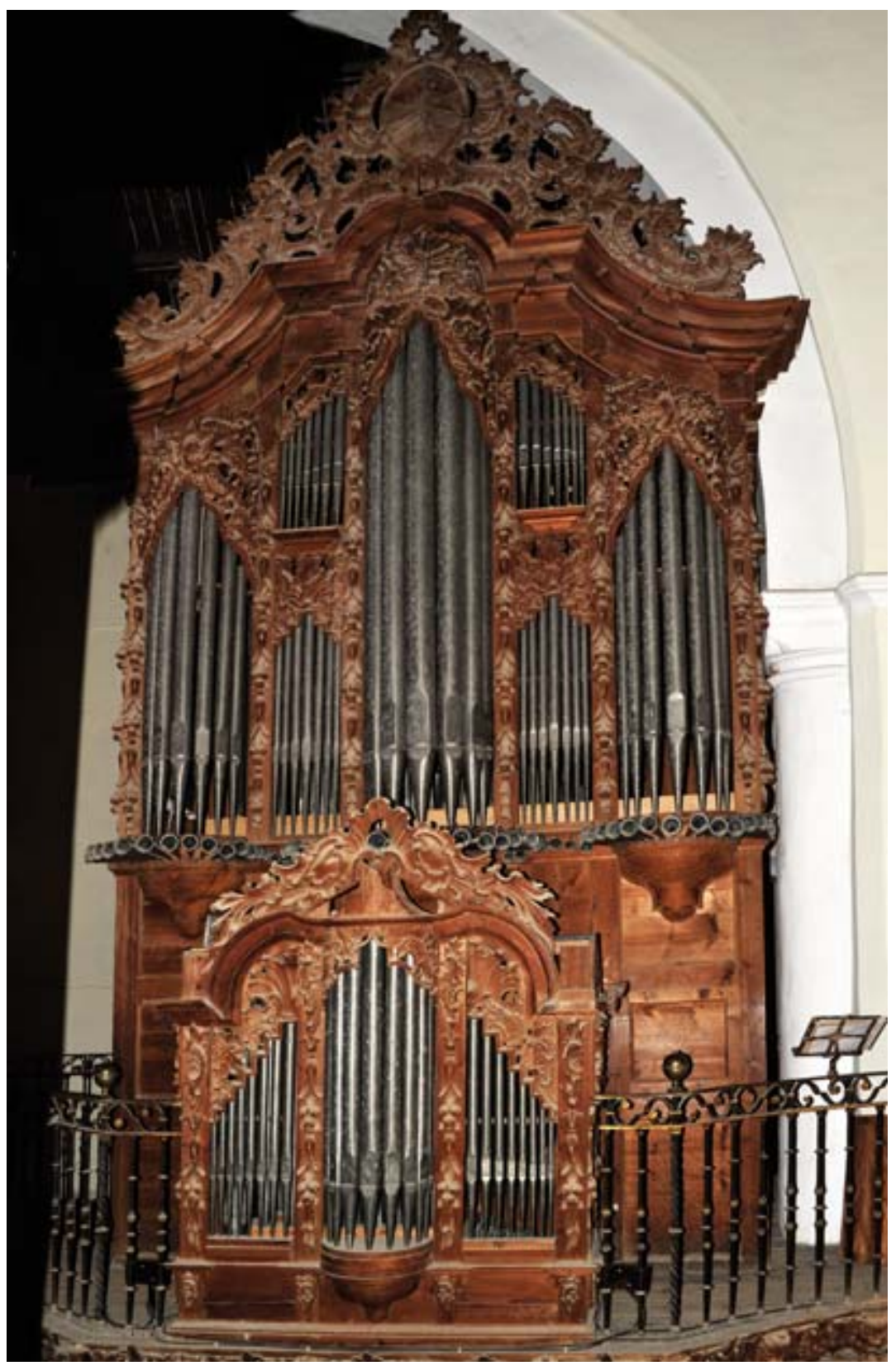

Fig. 2. Caja del órgano Chavarría del lado del evangelio. Año 1765. Iglesia Parroquial de San Juan. Marchena (Sevilla). Fotogr.: Juan Antonio Campos Espina.

largo. La cadereta de un solo cuerpo tiene paralelismos con el gran órgano. Posee tres castillos con un torreón en su parte central. Se trata de una pieza simétrica en la que se repiten los elementos estructurales y decorativos como el entablamento mixtilíneo, la guirnalda de frutos y la rocalla, en menores dimensiones. Se remata por una crestería de rocalla por encima de la cornisa. Sus 


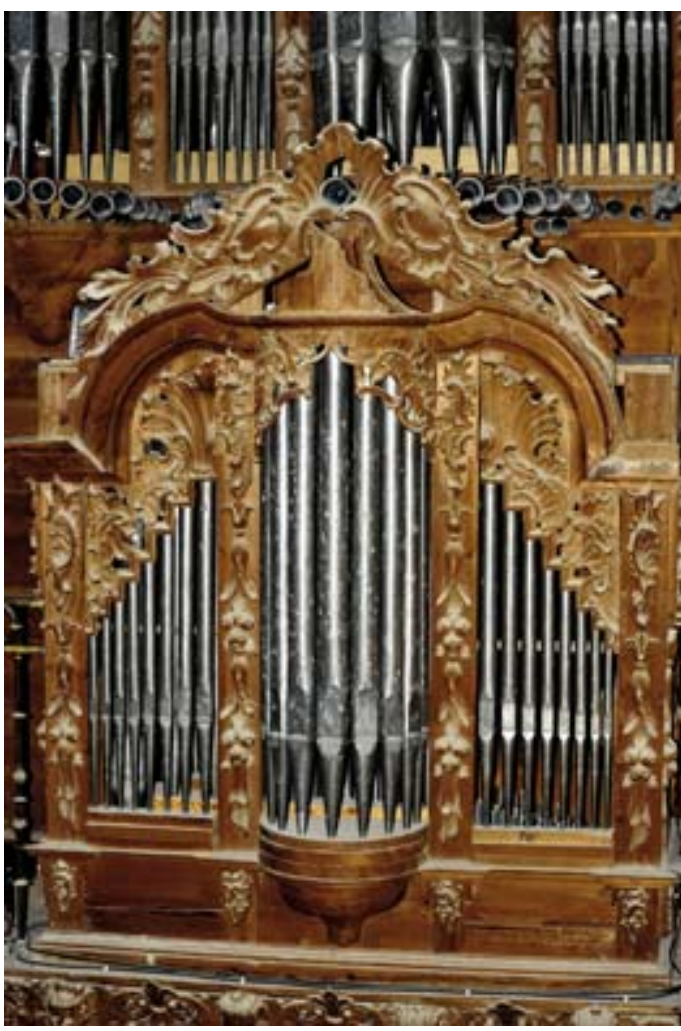

Fig. 3. Cadereta del órgano Chavarría (det.). Fotogr: Juan Antonio Campos Espina. tubos de mayores dimensiones tienen cuatro pies, casi metro y medio. También se han colocado dos castillos de tubos decorativos en sus laterales y que cumplen la misma función que en el gran órgano (fig. 3).

Poniendo en relación este instrumento con los que se conocen y conservan de Chavarría o aquellos atribuibles se aprecian claras similitudes en el planteamiento y resolución del mueble. Así sucede con la caja de la iglesia de Ntra. Sra. de Gracia de Espera (Cádiz) que se construye en 1764 y presenta en su cuerpo principal un torreón central, cinco castillos y dos dobles ${ }^{25}$. Sobre éste un ancho entablamento roto en su parte principal por una cartela rodeada de hojarasca, al igual que rematando la división entre sus castillos. Ésta se hace a base de una guirnalda de frutos muy semejante en ambos muebles. Aunque de menores proporciones y sin la existencia de cadereta, la única diferencia está en el empleo de la hojarasca en el de Espera, sustituidas en éste otro por la rocalla, elemento que denota la evolución estilística. En el primero se aprecia un mascarón bajo el torreón, elemento que no poseen los de Marchena, quedando éstos sin tallar. El cuerpo bajo, en ambos casos, posee unos tableros geométricos sin decorar ${ }^{26}$.

Otro instrumento que guarda ciertas similitudes es el órgano del lado del Evangelio de la Parroquia de la Magdalena de Sevilla, perteneciente al antiguo convento dominico de San Pablo. Su caja es más esbelta que la de Marchena y su forma aparece más enmascarada por la decoración, el dorado de sus piezas y paneles pintados simulando placas marmóreas ${ }^{27}$. Sin embargo, tanto la estructura del gran órgano con cinco castillos, tres torreones y dos dobles, remates de los torreones, gran cornisa, ... así como la cadereta guardan paralelismos.

No obstante, en la ciudad vecina de Écija se dan formas de trabajar en estrecha relación con la talla de la caja analizada y convergen talleres de tallistas muy productivos ${ }^{28}$. Otro de los instrumentos, obra de Chavarría, se encuentra en la iglesia de Santa Bárbara de esa ciudad ${ }^{29}$. La caja la

${ }^{25}$ Para precisar la terminología descriptiva de este y otros instrumentos se ha seguido a CEA Galán, CHÍA TRIGOS, 1995: 15-16, 162.

${ }^{26}$ Se sabe que trabajaron dos carpinteros y un oficial, en acortar la caja y hacer unas piezas que faltaban, gracias a unos pagos registrados en el libro de fábrica de la Parroquia de Espera, libro de cuentas, año 1764, f. 86. No obstante, no se conocen sus nombres y posiblemente se tratase de tareas de adaptación de la caja al marco arquitectónico donde se ubicaría el órgano. Por tanto, no necesariamente vinculados al taller del organero. Se ha tenido acceso a estos datos recogidos en su día por Ramírez Palacios, a quien se lo agradecemos.

27 Tejedor FernÁndez, 1995: 42. Según éste, la imitación de jaspes y mármoles hace pensar que la caja fue redecorada a principios del siglo XIX.

${ }^{28}$ Fernández Martín, 1994. Herrera García, 1995: 334.

${ }^{29}$ Martín Pradas, 1993: 108. Según éste, Chavarría concluyó su trabajo en febrero de 1761.

Arch. esp. arte, LXXXVI, 343, JULIO-SEPTIEMBRE 2013, 181-200, ISSN: 0004-0428 
realizó Antonio González Cañero en $1761^{30}$. Se trata de una caja con idéntica distribución a la de San Juan de Marchena, sin embargo, más cargada de decoración. Presenta en su fachada cinco castillos con tres torreones y dos dobles y se remata por un entablamento sobre el que descansa una enorme crestería de decoración vegetal y rocalla. Entre los castillos corre una guirnalda de flores y frutos muy volumétricos, semejante a la del órgano de San Juan; aquí más acentuadas por el uso del ciprés, madera que contrasta con la caja hecha de pino, dándole un aspecto más plástico. Sobre el torreón central un gran medallón con una torre, símbolo de Santa Bárbara. A diferencia con la caja de Marchena, los torreones se completan en su parte inferior con rocallas.

Siguiendo su producción y la del taller familiar éste realizó todo tipo de muebles en madera, incluidas las cajas de órgano. Construyó en 1779 la caja de la iglesia de Santiago de la misma ciudad, aunque se trata de una obra del organero Francisco de Molina ${ }^{31}$. Si bien, es de mayores dimensiones, ésta guarda menos relación en sus elementos decorativos con la caja de Marchena que la anteriormente citada. A diferencia de la caja de Marchena añade dos castillos extremos. Sin embargo, los elementos decorativos se repiten como el uso de la rocalla, la cornisa mixtilínea muy voluminosa, el remate del mismo más decorado, que alberga la cruz de Santiago, ... De su proceso constructivo, se conoce que el mismo organero manifestó que la caja debía hacerse cargo algún tallista de la misma ciudad, pues "... hay en ella maestros hábiles en la facultad, que con todo primor desempeñarán su obligazión” y sería menos costosa ${ }^{32}$.

Por tanto, las relaciones entre estas cajas son evidentes. No se debe olvidar, que existían relaciones artísticas entre Marchena y Écija, pues uno de los componentes de la saga Juan José González Cañero, abuelo del tallista, había participado activamente en la traza y decoración de las yeserías del mismo coro. Al ser la producción del taller de los Cañero bastante amplia, debían participar en él un número variable de aprendices y oficiales, aunque no ha llegado hasta nosotros el nombre de ninguno ${ }^{33}$.

No obstante, y aún teniendo en cuenta las vías de investigación expuestas tampoco se debe descartar la referida a los tallistas que por entonces, trabajaban en Marchena y su zona de influencia. Nos referimos al caso de la familia Casaus, originarios de la localidad vecina de Paradas. Integrada por José Victorino, padre y sus hijos Francisco, Vicente y Bruno, todos realizaron alguna obra de talla en iglesias de localidades cercanas. Del padre de la saga se conocen algunas obras para las localidades de Paradas y Arahal, aunque no se conoce ninguna en Marchena ${ }^{34}$. Sin embargo, de su hijo Francisco además de sus obras en las citadas localidades, se conoce la realización del retablo de San José en la Parroquia de San Juan ${ }^{35}$, junto a la tribuna del órgano que más adelante se analizará. Volviendo a su padre, José Victorino, se conoce la realización de la sillería de la iglesia de la Magdalena de Arahal $^{36}$ y la caja del órgano del mismo templo ${ }^{37}$. De igual forma, y sin salir de la localidad vecina se pueden apreciar relaciones estilísticas con la caja del órgano de la iglesia de la Victoria.

A la colocación del órgano en el lugar que ocupa, precedió la construcción de la tribuna en la que intervino Francisco Navarro, maestro albañil, el carpintero Alonso Mesón y el herrero Juan de los Ríos ${ }^{38}$. Sus trabajos dieron como resultado una tribuna en forma de balcón corrido

\footnotetext{
${ }^{30}$ FernándeZ Martín, 2000: 56-57.

${ }^{31}$ Martín Pradas, 1992: 131-138. Se trasladó de su primitiva ubicación a los pies de la iglesia en el siglo XX.

32 Herrera García, 1995: 334.

33 Fernández Martín, 2000: 26-27.

${ }^{34}$ Halcón, Herrera, Recio, 2000: 218.

35 Ramos SuÁrez, 2001: 266-267.

${ }^{36}$ Hernández Díaz, Sancho Corbacho, Collantes de Terán, 1939: 166.

37 Villa Nogales, Mira Caballos, 1993: 61.

${ }^{38}$ Así se deduce del documento encontrado en el secreto del órgano y de los asientos en los libros de fábrica de la
} parroquia. 
con balaustrada de hierro a la que se accede por una escalera de caracol embutida en el muro del trascoro del lado del evangelio. Ese modelo de tribuna para ubicar el órgano se emplea a partir del barroco de forma general ${ }^{39}$. Una vez concluidos los trabajos, y en la visita que se practicó en septiembre de 1767 por el visitador don Domingo Pérez de Ribera mandó se tallasen las cabezas de las vigas que sostenían el órgano, pues resultaban feas e imperfectas ${ }^{40}$. En febrero de 1772 se pagó a Francisco Casaus, tallista de la villa de Paradas por la realización de la tribuna. Su trabajo consistió realmente, además de componer varias piezas del coro, en "cubrir las bigas de lo mismo y concluir la tribuna del órgano"41. Tras su intervención el conjunto ganó en gusto y belleza. Se tallaron las vigas por todas sus partes y las cabezas de las mismas se remataron con rostros humanos con la boca entreabierta en actitud de soplar, como si éstos fuesen los fuelles que hacen sonar al instrumento. Los hierros que sirvieron para sostener la balconada también se cubrieron de madera. Más tarde, en agosto de ese año se pagó a Francisco Lozano Palomino por pintar las barandas del órgano ${ }^{42}$ (fig. 4).

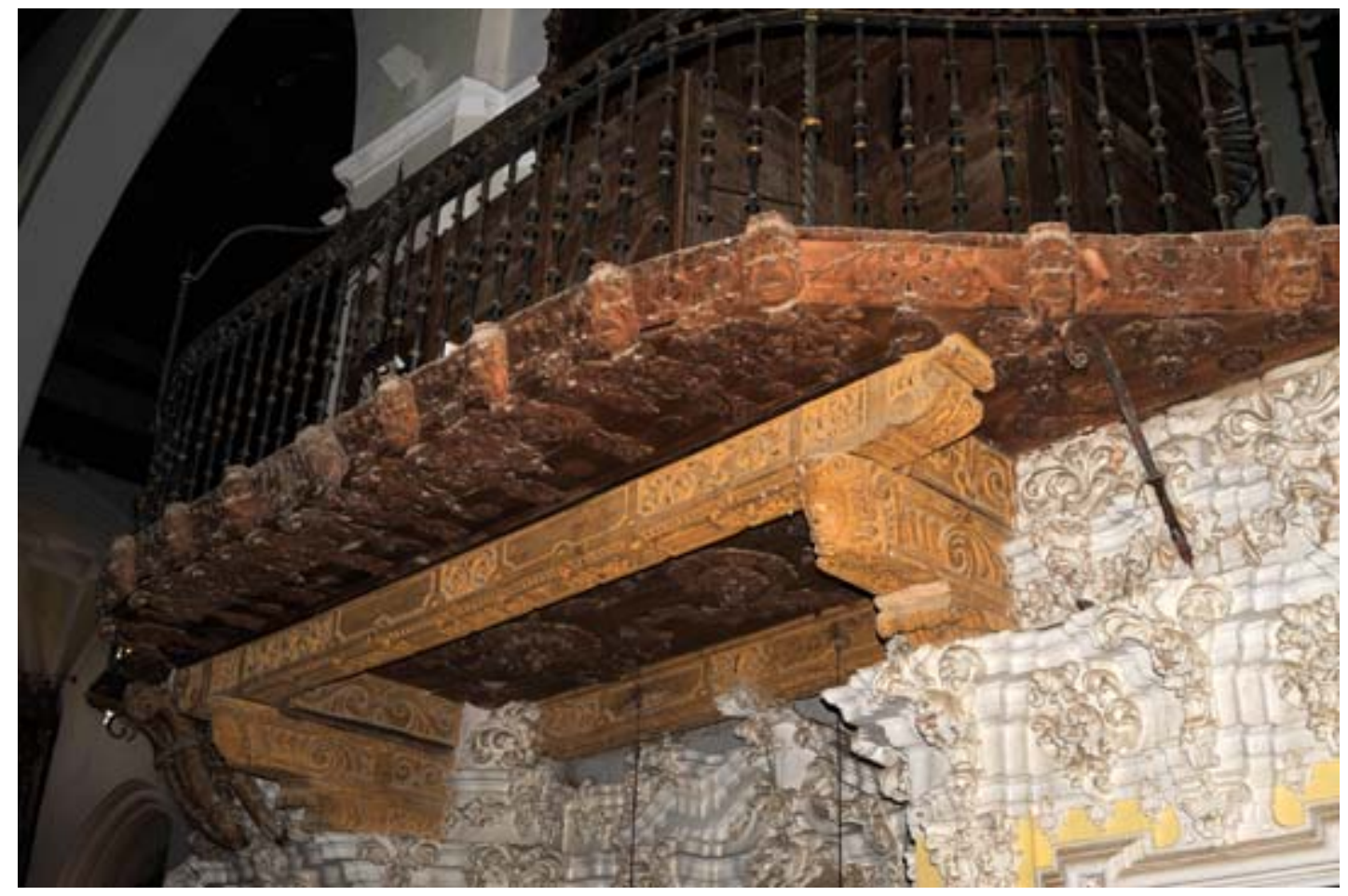

Fig. 4. Francisco Casaus y Juan de los Ríos. Tribuna del lado del evangelio. Año 1772. Iglesia Parroquial de San Juan. Marchena (Sevilla). Fotogr.: Juan Antonio Campos Espina.

\footnotetext{
39 Bonet Correa, 1983: 253.

40 APSJM, libro de mandatos de visitas, F-29, s/f. Visita realizada en 1 de septiembre de 1767, Mandato n. 7.

${ }^{41}$ ArenILlas, 2003: 174. APSJM, libro de cuentas de fábrica, A-34, Años 1770-1772, pp. 328-329.

${ }^{42}$ APSJM, libro de cuentas de fábrica, A-34, Años 1770-1772, pp. 357-358. Al pintor se le pagaron trescientos setenta y cinco reales por su trabajo.
}

Arch. esp. arte, LXXXVI, 343, JULIO-SEPTIEMBRE 2013, 181-200, ISSN: 0004-0428 
Recientemente, cuando en 1997 se procedió a la restauración y recuperación del instrumento, no se llevó a cabo la restauración de su caja ${ }^{43}$. Aún se reflejan en ella los numerosos grafitis que durante el pasado siglo dejaron algunos individuos vinculados al instrumento o al templo ${ }^{44}$.

\section{El órgano de la epístola o Rodríguez}

Sólo habían transcurrido treinta años del estreno del órgano Chavarría cuando a fines de 1795 se planteó la construcción de uno nuevo. Tras la escritura de obligación entre el organero Francisco Rodríguez y la fábrica de la localidad en febrero de 1796 se inicia su construcción ${ }^{45}$. Una vez planteada, surgió la intención de ampliarlo, materializándose otro contrato con el mismo organero en junio de $1799^{46}$. Tras ello, se decide la construcción de una caja que lo albergase. Por tanto, el organero se encargó de reconocer el plan y dibujo de la misma en enero de $1798^{47}$. Y así, se hizo contrato entre la fábrica parroquial y el tallista Francisco de Acosta, maestro mayor del Arzobispado hispalense entre el día 9 y 14 de enero de $1799^{48}$. Concretamente, debió ser antes del 12 de enero de ese año, ya que ese día se le hizo un primer pago por valor de 8.436 reales y 12 maravedíes $^{49}$.

Francisco de Acosta, cuyo verdadero nombre era Francisco de las Llagas Acosta, y que para diferenciarlo de su padre, Francisco de Acosta "el mayor", se ha convenido en llamar "el mozo," nació en Sevilla en 1764 y era hijo de Francisco y Felipa de Cáceres (fig. 5). Se casó con Andrea González en 1788 y al año siguiente sustituyó a su padre como maestro mayor del Arzobispado ${ }^{50}$. Como ya se ha dicho, aunque su padre y tío fueron barrocos, él fue neoclásico ${ }^{51}$. Se formó en el taller familiar realizando obras en madera tales como retablos, cajoneras, cajas de órgano, ... al igual que lo habían hecho sus antecesores ${ }^{52}$.

${ }^{43} \mathrm{Al}$ parecer, el trabajo se limitó a la limpieza exterior del polvo de todo el mueble con brochas finas y aspirador. Grenzing, s/f: 9. Además se apunta que "el exterior y su nutrición tiene que ser en su caso consolidado o restaurado por un especialista" circunstancia que aún no se ha dado.

${ }^{44}$ Escritos con grafito negro aún se pueden leer. Para un futuro, convendría una restauración de la misma.

${ }^{45}$ El organero Francisco Rodríguez se había desplazado a la localidad para valorar el órgano existente considerándolo desafinado, descompuesto e incapaz, y planteaba una reforma en el mismo. Sin embargo, el organero Juan de Bono consideraba que debía hacerse uno nuevo. ARCHIVO HISTÓRICO PROVINCIAL DE SEVILLA (AHPSE.), Protocolos Notariales, leg. 5225, ff. 55r.-62v. La escritura se firma el 4 de febrero de 1796. Como curiosidad, ese mismo día, el organero concierta la realización de otro órgano para la iglesia parroquial de San Pedro de Huelva. AHPSE, Protocolos Notariales, leg. 5225, ff. 48r.-54v. Para saber algo más sobre F. Rodríguez; Ramírez Palacios, 1987: 155, así como de las características técnicas del instrumento, AyARRa JARNe, 1998: 183-184.

${ }^{46}$ AHPSE, Protocolos Notariales, leg. 5228, ff. 344r.-349v.

${ }^{47}$ Se conserva copia del recibo pagado al organero por ese menester, APSJM, Fondo General, leg. LIX, exp. 3890. s/f., Marchena, 1 de enero de 1798. También APSJM, libro de cuentas de fábrica, B-10, Años 1796-1799, p. 336. Se le pagó la cantidad de ciento setenta y seis reales.

${ }^{48}$ La escritura del contrato entre Acosta y la fábrica de Marchena se sabe que se practicó ya que consta en los índices de las escrituras de José Gutiérrez de Ojeda. (oficio 7) AHPSE, Protocolos Notariales, leg. 18406, año 1799, letra F. Sin embargo, al consultar el legajo que corresponde a ese año, las escrituras que van del fol. 11 al 19 no se conservan en su lugar y el cuaderno que debería recogerlas está descosido. AHPSE, Protocolos Notariales, leg. 5228, ff. 11-19. Únicamente se conserva el f. 17, que no corresponde al tema que se analiza.

49 APSJM, Fondo General, leg. LIX, exp. 3890. s/f.

${ }^{50}$ Ros GonzÁlez, 1999: 41. Para conocer aspectos familiares de los Acosta, Pleguezuelo Hernández, 1994: 131-159.

${ }^{51}$ Halcón, Herrera, Recio, 2000: 200.

${ }^{52}$ Su padre, Francisco de Acosta "el mayor" realizó numerosas cajas de órganos entre las que se encuentran la de Almonaster la Real (Huelva) en 1779, la de los Jerónimos de Bornos (Cádiz), hoy en la Parroquia de Las Cabezas de San Juan y El Coronil (Sevilla) en 1780, trazas para la de Campillos (Málaga) en 1787, la del templo de Omnium Sanctorum (Sevilla) en 1788 y la de Puebla de Guzmán (Huelva) en 1789. Tal como se aprecia en ellas, poco a poco va depurando su estilo para desembocar en formas académicas. Halcón, Herrera, Recio, 2000: 205. 


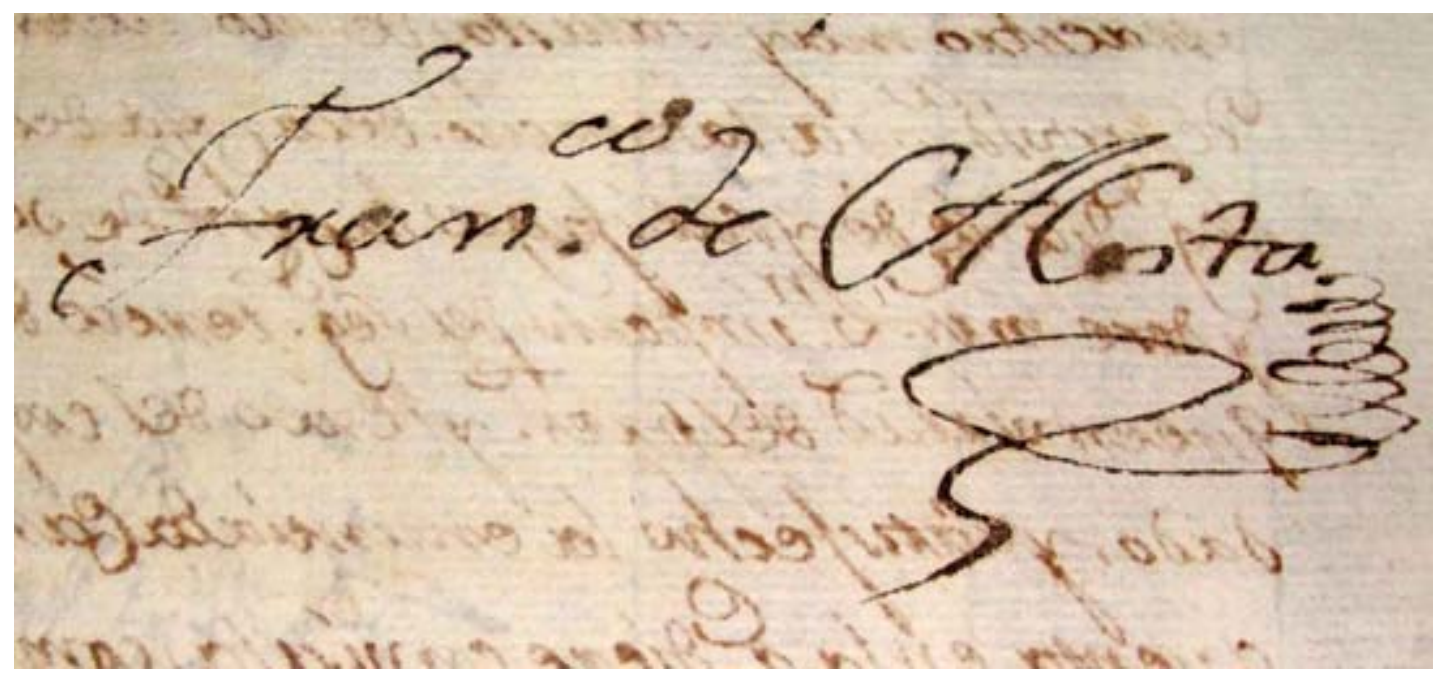

Fig. 5. Firma autógrafa de Francisco de Acosta "el mozo". Año 1798. APSJM, Fondo General, leg. LIX, exp. 3890. Fotogr.: el autor.

Son numerosas las obras que forman parte de su producción artística como retablos, monumentos, cajoneras para sacristías, ... así como su participación en el reconocimiento de numerosas obras, fruto de su cargo en el Arzobispado hispalense. Para la localidad de Marchena y más concretamente para el templo donde se encuentra este órgano, Acosta diseñó y construyó un monumento eucarístico y el cancel de la puerta situada en el lado de la epístola ${ }^{53}$. En el campo de las cajas de órgano construyó la de Bollullos Par del Condado (Huelva) y la de la Algaba (Sevilla) en 1789, reconoció y apreció el diseño que hizo el tallista Miguel Guisado para la caja del órgano de La Puebla de Cazalla (Sevilla) en 1793, también hizo la de la Parroquia de Las Cabezas de San Juan (Sevilla) desaparecida y sustituida por la que hizo su padre para los Jerónimos de Bornos y la de Santiago de Carmona (Sevilla) en $1794^{54}$.

Al primer pago efectuado al tallista siguió otro realizado en mayo de $1799^{55}$, otro a cuenta del último pago en febrero de $1800^{56}$ y el resto del tercero en mayo de 1801 . Al total de lo pagado, que ya sumaban veinticinco mil seiscientos reales, se añadieron mil doscientos más "por equidad ... y por el aumento que tuvo la referida caxa" ${ }^{57}$. Analizando por tanto el costo de la misma correspondía aproximadamente a un tercio del gasto en que se presupuestó el instrumento en $\mathrm{si}^{58}$.

53 Ramos SuÁrez, 2011: 25-29

${ }^{54}$ Para conocer su producción artística de fines del siglo XVIII, Ros GonZÁlez, 1999: 41-80.

55 APSJM, Libro de cuentas de fábrica, B-10, Años 1796-1799, pp. 333-334.

${ }^{56}$ APSJM, Libro de cuentas de fábrica, B-11, Años 1799-1802, $1^{\mathrm{a}}$ visita, pp. 251-252. Esta vez se le entregaron dos mil reales como parte del tercer y último pago.

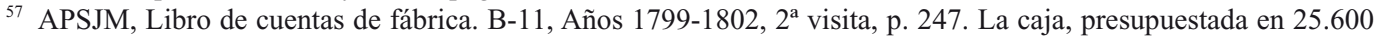
reales, costó 26.800 reales con la reforma y mejoras realizadas.

${ }^{58}$ El instrumento se apreció por el maestro organero en 80.900 reales, incluidos ya los 38.000 reales de su ampliación. APSJM, Libro de cuentas de fábrica, B-10, Años 1796-1799, p. 331. Si la tónica habitual era que la construcción de la caja supusiera un tercio menos que la parte musical, en este caso su costo supuso un tercio respecto al del instrumento. Bonet Correa, 1983: 246. 


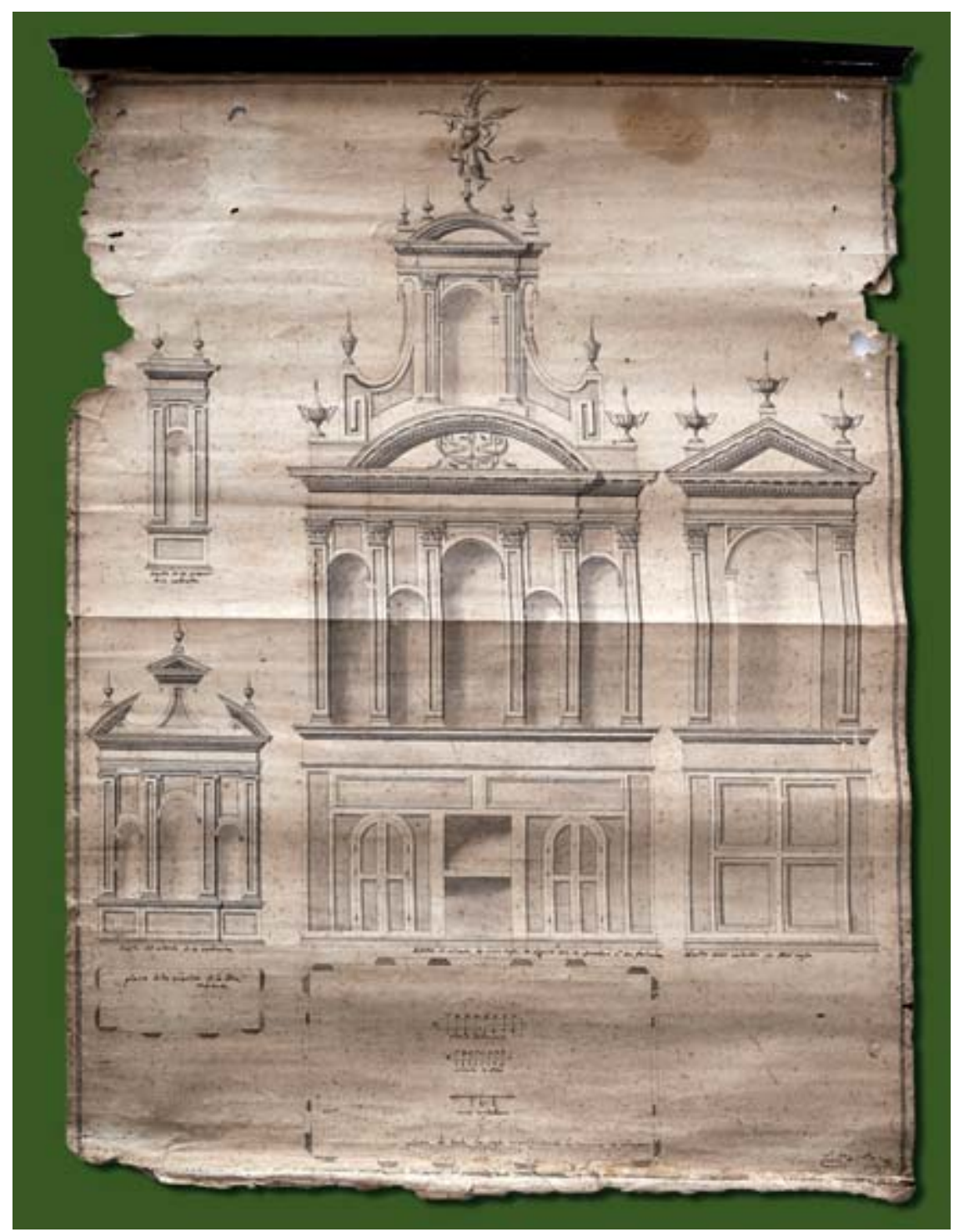

Fig. 6. Francisco de Acosta “el mozo”. Trazas del órgano Rodríguez del lado de la epístola. Año 1799. Iglesia Parroquial de San Juan. Marchena (Sevilla). Fotogr.: Juan Antonio Campos Espina.

La caja, de la que se han conservado sus trazas ${ }^{59}$ (figs. 6-7-12), realizada en pino presenta dos fachadas semejantes, una al coro (fig. 8) y la otra a la nave, salvo en su remate (fig. 9). En su organización se sigue el esquema de las espadañas. Desde el coro se aprecia el primer cuerpo que corresponde al lugar donde se ubica la consola y las puertas de entrada al arca de viento y al instrumento

${ }^{59}$ Se trata de un interesante dibujo en papel verjurado $(815$ x $630 \mathrm{~mm}$.) en tinta negra y firmado en su ángulo inferior derecho "Francisco de Acosta/ me fesis". El dibujo presenta la fachada del gran órgano que da al coro especificándose 
en sí. Está decorado de forma sencilla con cuarterones simétricos. El cuerpo donde se ubica el flautado o principal se articula en cinco vanos o arcos de medio punto, que se corresponden con los castillos, mediante seis pilastras de orden corintio. El vano central de mayor luz y los laterales simétricos, siendo los cercanos al castillo central de menores dimensiones que los colocados a los extremos. Sobre los castillos se colocan paneles de celosías con decoración vegetal simétrica. Entre el primer cuerpo y el principal se ubica la trompetería al modo hispano, hasta en tres niveles. Este cuerpo principal posee un entablamento corrido, con frontón curvo que solo recoge las tres calles centrales. Sobre las laterales corren unos pedestales rematados en jarras. El tímpano del frontón lleva en su interior una cartela con una cruz de malta o de San Juan, escudo del titular del templo. El cuerpo superior del órgano presenta un vano o arco de medio punto ordenado por pilastras corintias, un entablamento corrido y un frontón curvo rematado por la figura de un ángel trompetero $^{60}$ y unos jarrones (fig. 10). Los costados del órgano también presentan en su cuerpo bajo una decoración de cuarterones. El cuerpo principal es un arco de medio punto que alberga un castillo de tubos con dos pilastras corintias a ambos lados. Sobre éste corre un entablamento y un frontón triangular. Se remata con tres jarras, dos en los extremos y una en su parte superior.

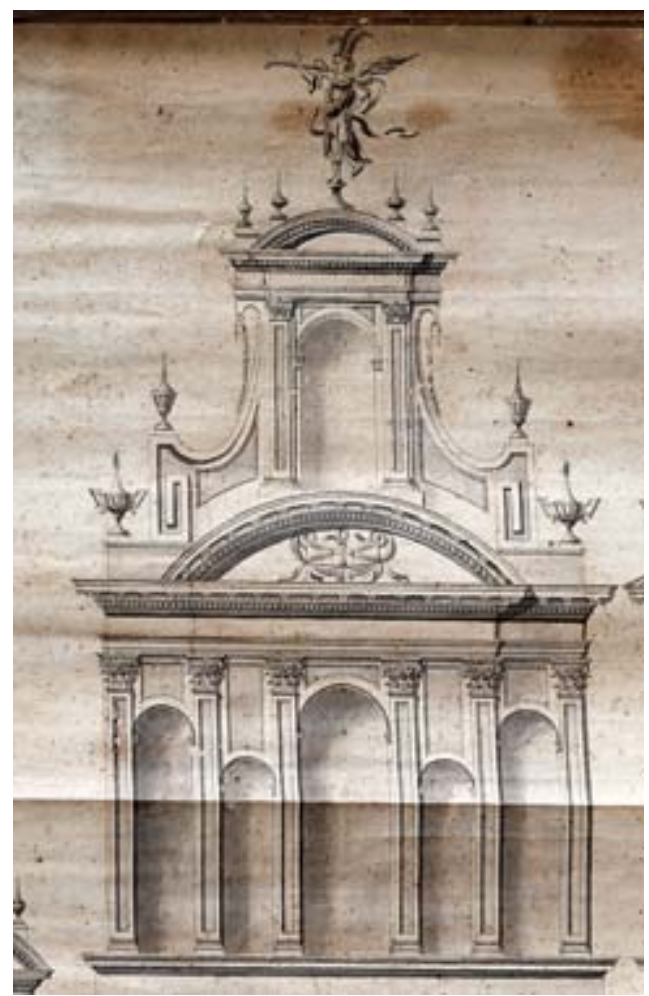

Fig. 7. Francisco de Acosta "el mozo". Trazas del órgano Rodríguez (Det. de la caja principal). Año 1799. Iglesia Parroquial de San Juan. Marchena (Sevilla). Fotogr.: Juan Antonio Campos Espina.

en la leyenda "diseño de alzado, de una caja, de olgano (sic) sea de ejecutar por dos fachadas", debajo de éste la planta de la caja denominada como "plano de toda la caja manifestando los masisos de pilastras" y en su interior se dibujan las distintas escalas empleadas "escala de modulos", "escala de [dichos]" y "vara castellana". A su derecha está dibujado el "diseño de los costados de dicha caja" y a la izquierda el "diseño del alzado de la cadereta", la planta o el "plano de los masisos de la dicha cadereta" y en su parte superior la traza correspondiente al "diseño de los costados de la cadereta." Se encuentra actualmente en el archivo de la Iglesia Parroquial de San Juan. Presenta algunas roturas, manchas de diversa consideración y está unido a un listón en su parte superior que hace las veces de marco, con posibilidad de desprenderse. Requiere, por tanto, de una restauración y colocación en un mueble-marco que reúna las condiciones necesarias para su conservación y exposición. La necesidad de ésta cobra interés ya que se trata de una pieza u obra de arte en sí misma y son contados los diseños de estos instrumentos que han llegado hasta nosotros. JAMBou, 1983: 216. Según éste, en la mayoría de los casos estas trazas no se conservan. Del Arzobispado hispalense únicamente se conocen las trazas del órgano de Campillos (Málaga), el de San Juan de Écija y éste.

${ }^{60}$ Varias son las figuras que pueden rematar las cajas de órgano. Con su colocación en ese lugar se han querido ver diversas connotaciones simbólicas. VICENTE, 1999: 86-87. Aunque no se conserva la escritura de la caja para definir qué imagen pretendía presentar el tallista, si se conocen otras en las que define qué personaje se quiere representar. Concretamente, en la caja que hizo para la iglesia de Bollullos Par del Condado (Huelva) se dice "Sobre la voluta, entre las dos pilastras, va colocado un muchacho figurado, ademán de tocar una trompeta, para darle gracia a la fachada y diferenciar, no sean todos los remates de talla"; en el caso de la caja de La Algaba (Sevilla) se dice "el remate de en medio será una estatua a especie de un armado fingiendo ademán de trompetero, que será para su mayor vista." Ros GonzÁLEZ, 1999: 45, 49. Por lo que respecta a su objetivo, era meramente decorativo, sin especificarse ningún fin simbólico. 


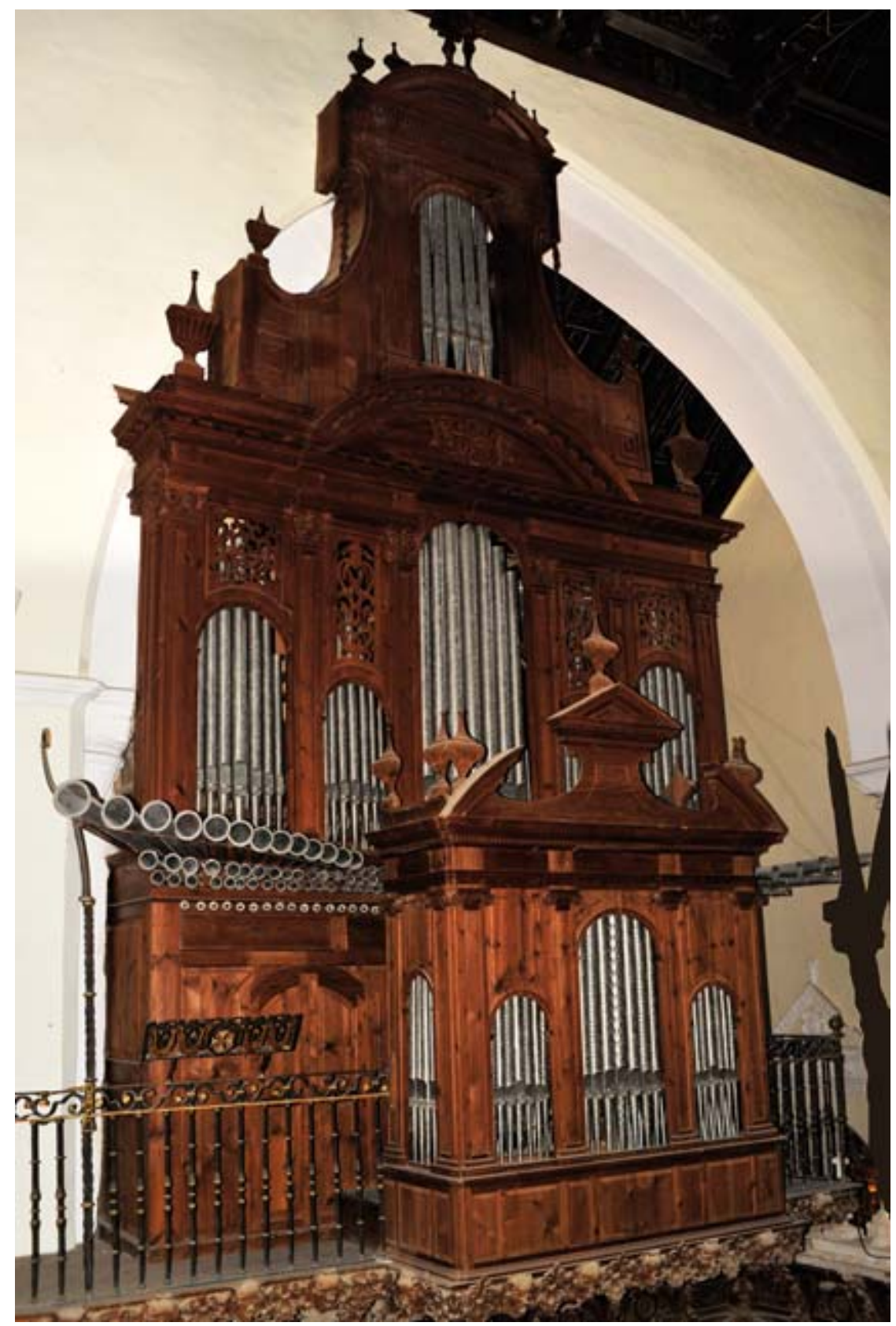

Fig. 8. Francisco de Acosta "el mozo”. Caja del órgano Rodríguez. Lado del coro. Año 1801. Iglesia Parroquial de San Juan. Marchena (Sevilla). Fotogr.: Juan Antonio Campos Espina.

Por lo que respecta a la cadereta, presenta decoración en tres de sus frentes, quedando el interior donde se sienta el organista, ocupado por unas puertas de cuarterones (figs. 11-12). La fachada está formada por un plinto sobre el que descansan cuatro pilastras de orden jónico y tres castillos 
de tubos, siendo el central de mayor tamaño y los laterales simétricos. Sobre ellos se dispone un entablamento corrido rematando en un frontón curvo partido, surgiendo del tímpano un edículo con frontón triangular. Unas ánforas sirven de acróteras. Los costados de la cadereta presentan el mismo orden de pilastras, rematándose por un antepecho con idénticos jarrones a eje con las pilastras de los extremos. A ese diseño y estilo de la cadereta se une la decoración que presentan los tubos que la configuran. Se trata de "tubos entorchados" ${ }^{\prime 61}$ con motivos geométricos, y que hacen contraste de luces y sombras, tan del gusto y estética neoclásicos. En definitiva, nos encontramos ante una obra arquitectónica neoclásica, que recuerda algunos modelos arquitectónicos sevillanos de principios del siglo XVII ${ }^{62}$.

Es evidente que hay una evolución entre la primera caja que realizó Acosta y la que se analiza. Por lo que respecta a la caja del órgano de Santa María de Arcos, realmente no se sabe qué pudo aportar Acosta, ya que la caja fue realizada por Miguel Vergara y parece que su trabajo consistió en plantear arreglos ${ }^{63}$. Por lo que respecta al órgano de Bollullos Par del Condado (Huelva) no se conserva y el de La Algaba al plantearlo su padre, no define claramente su estilo. Tampoco se conserva el de La Puebla de Cazalla que reconoció y apreció $^{64}$, ni el que hizo para la iglesia de Las Cabezas de San Juan. En cambio, aún se conserva la caja del órgano de Santiago en Carmona. Realizada en 1794 presenta paralelismos con la caja de Marchena, si bien es de proporciones más reducidas. Consta de dos cuerpos, situándose la consola en el primero y los tubos del principal en tres castillos de medio punto, separados por pilastras corintias. Entre ambos cuerpos se situaban tres hileras de trompetería, hoy desaparecidas. Se remata con un frontón triangular con dos pináculos piramidales en sus extremos. Aunque su resolución es más sencilla, incorpora algunos elementos dorados como los capiteles, guirnaldas, ...

La relación no se circunscribe a elementos decorativos de las cajas sino que también se aprecian similitudes en otras obras realizadas por éste. Es el caso de los remates del desaparecido retablo

${ }^{61}$ Es una forma de trabajar los tubos por el organero Rodríguez. Además de este ejemplo, los empleó en los órganos de la iglesia de Santa María de Arcos de la Frontera y de Ntra. Sra. de la O en Sanlúcar de Barrameda, ambos en Cádiz. En éstos, además en los tubos de fachada del gran órgano.

${ }^{62}$ Sobre el respecto, véase un libro que recoge bocetos de modelos arquitectónicos de esa época. Fernández Martín, 2003: 123-129. Los dibujos de las láminas 24 a 26 tienen elementos semejantes a los de la caja del órgano y de la cadereta.

${ }^{63}$ Cen Galán, Chía Trigo, 1995: 51.

${ }^{64}$ Este órgano fue realizado por el organero Francisco Rodríguez, si bien la caja fue realizada por el tallista Miguel González Guisado siguiendo el diseño de Francisco de Acosta. Para conocer su proceso constructivo vid. Retamero MoLINA, 2010: 359-366, así como para el contrato y descripción de la caja. Ros GoNZÁlez, 1999: 399-403.

Arch. esp. arte, LXXXVI, 343, JULIO-SEPTIEMBRE 2013, 181-200, ISSN: 0004-0428 


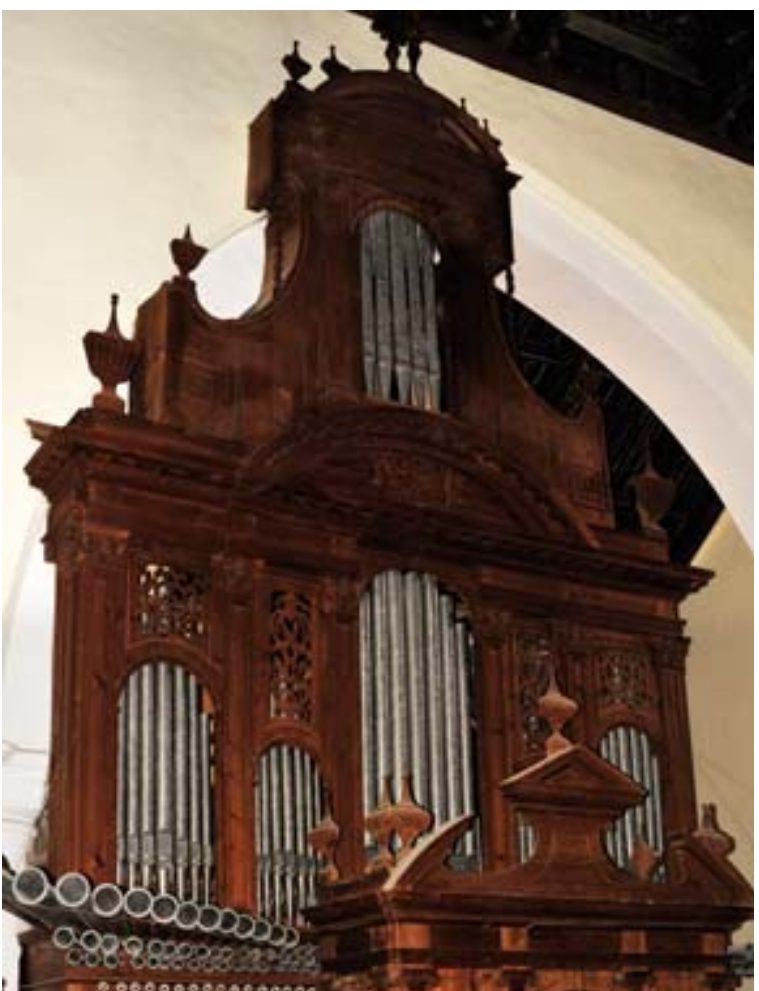

Fig. 10. Francisco de Acosta "el mozo". Caja del órgano Rodríguez. Cuerpo superior. Año 1801. Iglesia Parroquial de San Juan. Marchena (Sevilla). Fotogr.: Juan Antonio Campos Espina. mayor de la iglesia Parroquial de Ntra. Sra. de Consolación de la localidad de Aznalcóllar (Sevilla) o la cajonera que realizó para la Parroquia de Espera (Cádiz). Igualmente, se han encontrado relaciones entre esta caja y otras realizadas por el mismo tallista con posterioridad a la que se estudia. Así la cadereta que hizo para la iglesia parroquial de Lebrija (Sevilla) es de idéntica estructura y decoración, aunque con mínimas diferencias, sus pilastras son corintias, no presenta los tubos entorchados y sus costados no tienen un castillo de tubos, sino una celosía de forma romboidal ${ }^{65}$.

Otros instrumentos que también realizó el organero Rodríguez muestran en sus cajas evidentes paralelismos con la forma de trabajar del maestro Acosta. Es el caso de la caja para la iglesia de Paradas (Sevilla) y la de Villamartín (Cádiz) ${ }^{66}$, más sencillas en su decoración, pero ambas de corte neoclásico. Si se confirmase su intervención, se vendrían una vez más, a poner en relación al mismo organero con el tallista.

Previas a la construcción de la caja se habían realizado gestiones sobre cómo sería el lugar donde se ubicaría el instrumento. Para ello se pensó y construyó una tribuna sobre la sillería del coro en el lado de la Epístola, tras la visita practicada en abril de 1798 por Santiago de la Llosa y Francisco del Valle, maestros mayores de albañilería y carpintería del Arzobispado ${ }^{67}$. Apreciaron las obras en veintidós mil doscientos reales ${ }^{68}$. Las de albañilería se hicieron entre junio y agosto de 1799 corriendo a cargo de José Bazán, alarife local ${ }^{69}$ y las de carpintería desde junio de 1798

${ }^{65}$ El órgano de la parroquial de Lebrija fue ampliado con la realización de una cadereta, también por el organero Francisco Rodríguez. AHPSE, Secc. Protocolos Notariales, leg. 5228, ff. 180-184v. Documento fechado el 5 de abril de 1799. Su caja corrió a cargo de Acosta. AHPSE, Secc. Protocolos Notariales, leg. 7188, ff. 734-738. Se protocolizó el día 11 de diciembre de 1800 .

${ }^{66}$ La construcción de ambos órganos se dilató sobremanera en el tiempo, ya que las primeras gestiones se inician en 1803 y no será hasta 1818 ó 1819 cuando se den por finalizados. Esta tardanza debió venir motivada por los acontecimientos acaecidos durante y tras la ocupación napoleónica. Para el proceso de construcción se ha consultado copias de parte de los expedientes de construcción que se conservan en el Archivo General del Arzobispado de Sevilla, que Ramírez Palacios me cedió generosamente. Concretamente, en el de Villamartín, se expone que por lo costosas que están las maderas para hacer la caja, se cuente con una que existe en el convento de San Agustín de Sevilla que “... por no venir al que el combento está fabricando mayor que el que tenía la bendan ...".

${ }^{67}$ Recibo de la visita practicada en 2 de abril de 1798. APSJM, Fondo General, leg. LIX. exp. 3890. s/f.

${ }^{68}$ APSJM, Libro de cuentas de fábrica, B-10, Años 1796-1799, pp. 328-329.

${ }^{69}$ Recibo pagado a José Bazán por el trabajo realizado con un oficial y tres peones que suman dos mil doscientos cincuenta y un reales y diecisiete maravedies. APSJM, Fondo General, leg. LIX, exp. 3890, s/f. 
hasta agosto del año siguiente por el carpintero Francisco Carrillo ${ }^{70}$. Por lo que respecta a las obras de herrería, corrieron a cargo de Diego de los Ríos, herrero y cerrajero de la localidad que tras hacer pequeñas piezas como la cerradura de la puerta que da acceso al citado órgano, el hierro para el enmaderado de la tribuna, ... materializó la baranda que corre por toda ella ${ }^{71}$. Sigue el mismo diseño de la tribuna opuesta, que realizó el herrero Juan de los Ríos, padre del artífice posiblemente incorporándole unos atriles decorados con guirnaldas y tondo con la cruz de San Juan en el centro. Nuevamente, en marzo de 1800, los maestros mayores del Arzobispado cursaron una visita de reconocimiento para comprobar "in situ" como transcurrían las obras de la tribuna ${ }^{72}$. Para finales de junio de 1801, la caja ya estaba asentada en su lugar haciéndose cargo de su colocación Sebastián Rodríguez ${ }^{73}$. Sin embargo, el instrumento como tal no debía estar acabado aún ${ }^{74}$. Aunque el órgano sufrió restauraciones a mediados y fines del siglo XIX, ésta debió centrarse en el instrumento ya que no se indica nada relativo a la caja ${ }^{75}$. Recientemente, y en 2004, ha concluido otro proceso restaurador iniciado hace años que ha devuelto al órgano su carácter primigenio. La caja tam-

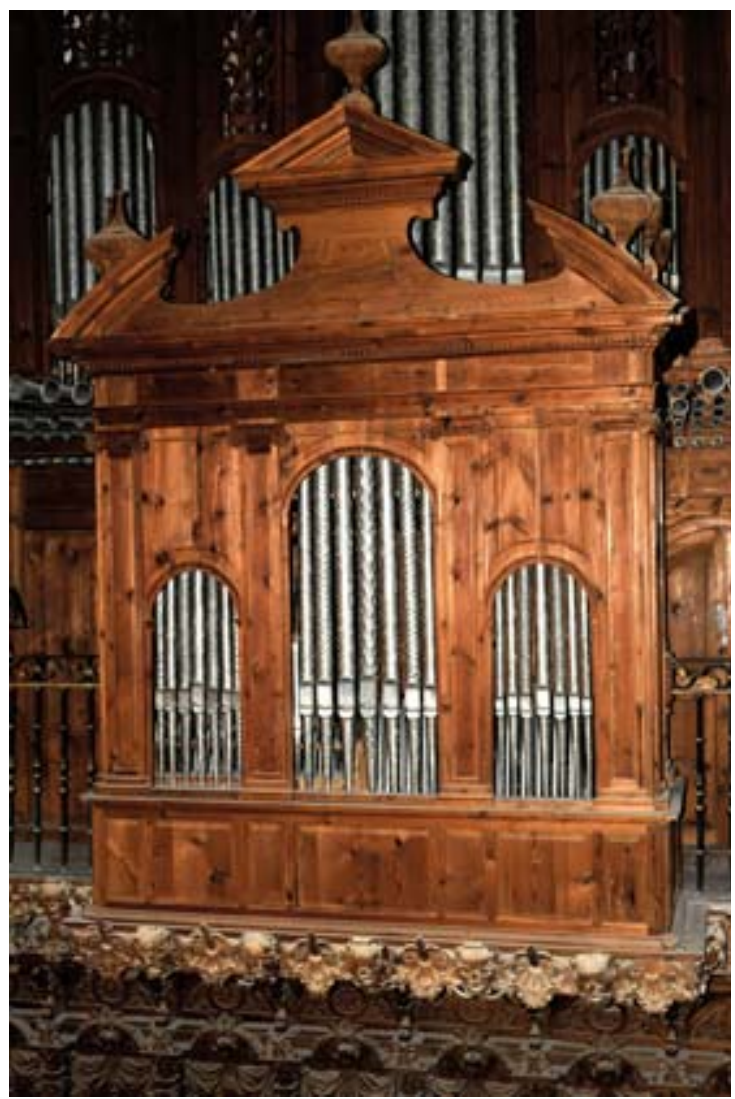

Fig. 11. Francisco de Acosta "el mozo". Cadereta del órgano Rodríguez. (det.). Fotogr.: Juan Antonio Campos Espina.

${ }^{70}$ Recibo pagado al carpintero por la compra de madera y otros materiales en Sevilla, así como por el trabajo de la tribuna. Le pagaron un total de ocho mil novecientos diez reales y trece maravedies. Las maderas que se trajeron del llamado "almacén del rey" fueron ochenta y dos tablas de madera de flandes de cuatro varas cada una, ocho palos gruesos de madera de segura de varios tamaños y otras más. APSJM, Fondo General, leg. LIX, exp. 3890, s/f.

${ }^{71}$ Recibo pagado a Diego de los Ríos el día 16 de agosto de 1799. APSJM, Fondo General, leg. LIX, exp. 3890, s/f. Se le pagaron cinco mil setecientos veinte y cuatro reales a cuenta por la baranda de la tribuna. Además, doscientos treinta y nueve reales por otras piezas. A.P.S.J.M, Libro de cuentas de fábrica, B-10, Años 1796-1799, pp. 334-335.

72 APSJM, Libro de cuentas de fábrica, B-10, Años 1796-1799, p. 253. Se trata de un pago de setecientos reales a Santiago de la Llosa y Francisco del Valle por la visita practicada a la tribuna y otras posesiones de la fábrica parroquial.

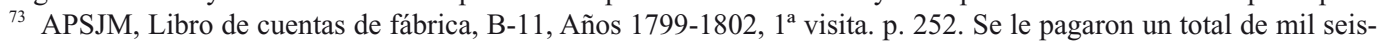
cientos treinta y seis reales.

${ }^{74}$ Concretamente en 1804 aparece un apunte donde se dice que "lo está haciendo" sin especificar nada más. APSJM, Libro de cuentas de fábrica, B-12, Años 1804, 1807 y 1813, Visita de fines de 1804, p. 58.

${ }^{75}$ Archivo General del Arzobispado de Sevilla, Administración General, (AGAS) leg. 284. Cuentas de Fábrica. Cuentas de culto de julio de 1850 a marzo de 1853. s/f. Estos gastos fueron para componer los fuelles. AGAS, Gobierno, Asuntos Despachados, leg. 368, noviembre de 1891, s/f. La reforma consistió en desmontar los pitos y poner nuevos fuelles. Los gastos correrían por cuenta de la Fábrica y donativos de los fieles. Se han localizado algunos de ellos, realizados por parte de vecinos de la localidad. Archivo Municipal de Marchena, Intervención, leg. 638, ff. 54v.-55r., fechados en noviembre de 1891. 


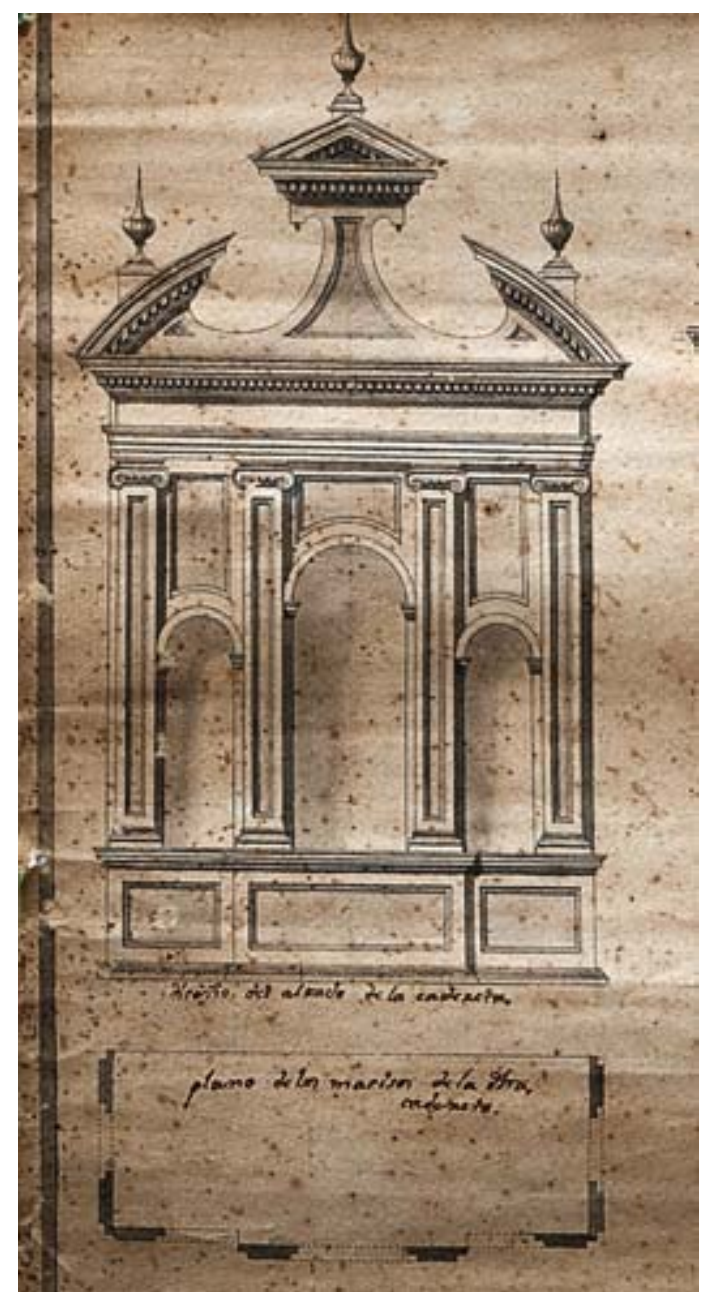

Fig. 12. Francisco de Acosta "el mozo". Trazas de la cadereta del órgano Rodríguez. (det.). Fotogr.: Juan Antonio Campos Espina. Fotogr.: Juan Antonio Campos Espina. bién ha sido sometida a un proceso de limpieza y consolidación.

Nos encontramos por tanto, ante dos piezas de gran interés no sólo por su valor arquitectónico sino también por su valor musical. Contemplamos así, unas obras de arte en las que se mezclan los elementos arquitectónicos, esculturales y decorativos y que alberga o encierra otra obra de arte. Ambas cajas reflejan el arte de su tiempo, su estilo, ... la arquitectura y escultura de su época, ... Concretamente en este caso, dos estéticas diferentes, antagónicas y enfrentadas aquí directamente con un mismo cometido, el de servir a la música. Son arquitecturas para la música.

Tanto el continente como el contenido han sido motivo de preocupación en lo que a conservación patrimonial se refiere. Para ello, en los últimos años se han acometido la recuperación histórica de los instrumentos y se han conservado sus cajas. Así, ambos han llegado hasta nosotros sin sufrir alteraciones. Y, aunque el trabajo realizado es mucho e importante, queda la labor de conocer, apreciar y valorar aquello que se posee para legarlo a las generaciones venideras ${ }^{76}$.

\footnotetext{
${ }^{76}$ Esperamos que con este trabajo se haya contribuido a un mejor conocimiento sobre los muebles que guardan estos instrumentos, para que unos como otros no pasen desapercibidos. Quisiera mostrar mi agradecimiento a don Juan R. Gallardo, párroco de la iglesia de San Juan, por las facilidades dadas a la hora de consultar los fondos del archivo parroquial, a don Juan Antonio Campos Espina por las imágenes que ilustran este trabajo y a doña Yolanda Ramírez Fernández por la traducción del resumen.
} 


\section{BIBLIOGRAFÍA}

Arenillas, Juan Antonio, "En torno a la arquitectura religiosa del siglo XVIII en Marchena" Actas de las VII Jornadas sobre Historia de Marchena. Politica e Instituciones. El Poder Eclesiástico. Marchena, Ayuntamiento, 2003, pp. 172-174.

Ayarra Jarne, José Enrique (dir.), Órganos en la provincia de Sevilla. Inventario y catálogo. Granada, Junta de Andalucía, 1998.

Bonet Correa, Antonio, "La evolución de la caja de órgano en España y Portugal", El Órgano Español. Actas del Primer Congreso, Madrid, Universidad Complutense, 1983, pp. 243-354.

Cea Galán, Andrés; Chía Trigos, Isabel, Órganos en la provincia de Cádiz. Inventario y catálogo, Granada, Centro de Documentación Musical de Andalucía, 1995.

Fernández Martín, M. Mercedes, El Arte de la madera de Écija durante el siglo XVIII, Écija, Ayuntamiento, 1994.

Fernández Martín, Mercedes, Los González-Cañero. Ensambladores y entalladores de La Campiña, Sevilla, Diputación, 2000.

Fernández Martín, María Mercedes, Dibujos Sevillanos de Arquitectura de la Primera mitad del Siglo XVII, Sevilla, Universidad, 2003.

Grenzing, Gerhard, Memoria de la restauración del órgano de la Parroquia de San Juan de Marchena (Sevilla) Lado del Evangelio, sin fechar, sin publicar. Archivo Parroquial de San Juan de Marchena. Original mecanografiado. 31 pp. + ilustr.

Halcón, Fátima; Herrera, Francisco; Recio, Álvaro, El retablo barroco sevillano, Sevilla, Universidad, 2000.

Hernández Díaz, José; Sancho Corbacho, Antonio; Collantes de Terán, Francisco, Catálogo arqueológico y artístico de la Provincia de Sevilla, Sevilla, Servicio de defensa del Patrimonio Artístico Nacional Zona 4, 1939, I.

Herrera García, Francisco Javier: "Écija como centro artístico. Los tallistas del siglo XVIII", Actas del II Congreso de Historia de Écija en el siglo XVIII, Écija, 1995, pp. 331-340.

Jambou, Louis, "Reflexiones sobre trazas y documentos organísticos", El Órgano Español. Actas del Primer Congreso, Madrid, Universidad Complutense, 1983, pp. 215-242.

Martín Pradas, Antonio, "El órgano de la iglesia parroquial de Santiago el mayor de Écija”, Atrio, n. 4, Sevilla, 1992, pp. 131-138.

Martín Pradas, Antonio, Las sillerías de coro en parroquias y conventos ecijanos, Écija, Gráficas Sol, 1993.

Martín Riego, Manuel, Diezmos eclesiásticos. Rentas y gastos de la mesa arzobispal hispalense (1750-1800), Sevilla, Caja Rural, 1990.

Martín Riego, Manuel, "Diezmos eclesiásticos en la Marchena del siglo XVIII. Su participación en la Mesa Arzobispal”, Actas de las VII Jornadas sobre Historia de Marchena. Politica e Instituciones. El Poder Eclesiástico, Marchena, Ayuntamiento, 2003, pp. 9-62.

Navascués Palacios, Pedro, Teoría del coro en las catedrales españolas. Discurso leído en el acto de su recepción pública el día 10 de mayo de 1998. Madrid, RABASF., 1998, pp. 133.

Navascués Palacios, Pedro, "Coros y sillerías: un siglo de destrucción” Descubrir el Arte, 15, Madrid, 2000, pp. 112-114.

Pleguezuelo Hernández, Alfonso, "Un retrato familiar de los Acosta en su segunda fase sevillana", Laboratorio de Arte, n. 7, Sevilla, Universidad, 1994, pp. 131-159.

Ramírez Palacios, Antonio, "Dinastías de organeros en Andalucía en los siglos XVIII y XX”, El Órgano Español. Actas del II Congreso Español de Órgano, Madrid, Ministerio de Cultura, 1987, pp. 149161.

Ramos Suárez, Manuel Antonio, "Juan del Castillo y Francisco Casaus, retablistas en la iglesia de San Juan Bautista de Marchena (Sevilla), Laboratorio de arte, n. 14, Sevilla, Universidad, 2001, pp. 266-267.

Ramos Suárez, Manuel Antonio, "El antiguo monumento del Jueves santo de la Parroquia de San Juan Bautista”, en Ramos Suárez, Manuel Antonio (comisario), Tantum ergo Sacramentum. Fe, Arte y Cultura en Marchena. cat. exp., Sevilla, Maratania, 2011, pp. 25-29.

Retamero Molina, Ana Ángeles, "El órgano histórico de la iglesia parroquial de La Puebla de Cazalla: una obra del organero Francisco Rodríguez", La Puebla de Cazalla. Una villa centenaria, una villa con historia, Madrid, El Viso, 2010, pp. 359-366.

Arch. esp. arte, LXXXVI, 343, JULIO-SEPTIEMBRE 2013, 181-200, ISSN: 0004-0428 
Ravé Prieto, Juan Luis, “Jerónimo de Balbás y la sillería coral de San Juan Bautista de Marchena" Revista de Arte Sevillano, 2, Sevilla, Obra Cultural de la Caja de Ahorros San Fernando, 1982, pp. 29-33.

Ravé Prieto, Juan Luis, Arte religioso en Marchena. Siglos XV al XIX, Sevilla, Junta de Andalucía, 1986. Ravé Prieto, Juan Luis, La Parroquia de San Juan Bautista de Marchena, Sevilla, Maratania, 2006.

Ros González, Francisco Sabas, Noticias de Escultura (1780-1800), Sevilla, Guadalquivir, 1999.

Sancho Corbacho, Antonio, Arquitectura barroca sevillana del siglo XVIII, Madrid, Consejo Superior de Investigaciones Científicas, 1984. Reimpr.

Tejedor Fernández, Luis, La Arquitectura de los órganos. Órganos barrocos de Sevilla, Sevilla, Colegio Oficial de Arquitectos de Andalucía Occidental, 1995.

Vicente, Alfonso de: "La ostentación de la armonía: temática de la decoración de las cajas de órgano en España”, Simposio internacional. El órgano histórico en Castilla y León. Valladolid, Junta de Castilla y León, 1999. pp. 73-105.

Villa Nogales, Fernando; Mira Caballos, Esteban, Documentos inéditos para la Historia del Arte en la Provincia de Sevilla, Sevilla, 1993.

Fecha de recepción: 25-V-2012

Fecha de aceptación: 14-I-2013 